\title{
Tongue Retraction in Arabic: An Ultrasound Study
}

\author{
Hamed Altairi ${ }^{1}$, Jason Brown ${ }^{1}$, Catherine Watson ${ }^{1}$, and Bryan Gick ${ }^{2}$ \\ ${ }^{1}$ The University of Auckland, ${ }^{2}$ The University of British Columbia
}

\section{Introduction}

A comprehensive theory of distinctive features must provide a direct relationship between phonetic and phonological representations of speech sounds, and must provide a phonetic explanation for the phonological processes that frequently occur by the sounds that constitute a natural class (Archangeli \& Pulleyblank 1994; McCarthy 1994). A common analysis of the emphatic consonants in Arabic is that they are pharyngealized (Davis 1995; Rose 1996), which predicts that both emphatics and pharyngeals should have a similar effect on neighboring vowels. This analysis, however, does not meet the above criteria in the face of empirical data. For instance, while there is a general ban on co-occurring pharyngeal consonants in roots (McCarthy 1994), pharyngeals are free to co-occur with emphatic consonants, suggesting that their phonetic properties are different. Another difference is that nasal $/ \mathrm{n} /$ and lateral $/ \mathrm{l} /$ are assimilated to the emphatics, but not to the pharyngeals. Moreover, the pharyngeals but not the emphatics lower neighboring vowels. These phonological behaviors open the question of what feature specification makes the emphatics distinctive. This paper opens with a discussion of some phonological aspects that distinguish emphatics and pharyngeals, suggesting that their phonetic properties are different. This is followed by a presentation of an ultrasound experiment conducted to investigate the tongue retraction implemented in these sounds.

Arabic emphatics are a complex set of sounds which include the emphatic coronals /ț/, /ṣ/, /ḍ/, /ọ/, which contrast with the non-emphatics $/ \mathrm{t} /, / \mathrm{s} /, / \mathrm{d} /, / \delta /$. There is evidence to suggest that the emphatic coronals and pharyngeals do not belong to the same natural class. For example, the emphatics are free to co-occur with the pharyngeals as shown in (1):

$$
\begin{aligned}
& \text { Co-occurrence of emphatics with pharyngeals } \\
& \text { a. [șaib] 'difficult' } \\
& \text { b. [hatab] 'firewood' } \\
& \text { c. [Yașab] 'nerve' } \\
& \text { d. [taћi:n] 'flour' }
\end{aligned}
$$

Another process involves the alveolar nasal $/ \mathrm{n} /$. This segment is articulated fully in a word or across word boundaries when adjacent to the gutturals (laryngeals, pharyngeals, and uvulars):

$$
\begin{aligned}
& \text { Nasal retention preceding gutturals } \\
& \text { a. [man Pa:mana] 'who believed' } \\
& \text { b. [min ha:d] 'any guide' } \\
& \text { c. [sami:Sun Sali:m] 'hearing and knowing' } \\
& \text { d. [Tali:mun haki:m] 'knowing and wise' } \\
& \text { e. [min } \chi \text { ajr }] \text { 'any good' } \\
& \text { f. [fasajunsidurn] 'Then they will nod their heads' }
\end{aligned}
$$

\footnotetext{
*Acknowledgement: We wish to acknowledge members of the Linguistics department and Interdisciplinary Speech Research Lab at UBC who helped facilitate this project, including Blake Allen, Noriko Yamane, Murray Schellenberg, Masaki Noguchi, Megan Keough, Avery Ozburn, and Jennifer Abel. This research was made possible by a University of Auckland Universitas 21 Doctoral Student Mobility Scholarship awarded to the first author. All errors are our own.
} 
However, when /n/ is followed by the uvular /q/ and the emphatic coronals (/ḍ/, /ț//ș/, / ð̣/), /n/ undergoes deletion, with the concomitant nasalization of the preceding vowel (Gouda 1988). This process occurs within a word or across word boundaries:
Nasal deletion preceding non-gutturals
a. [min qabl] [mĩ qabl] 'before'
b. [manșu:ra] [mã șu:ra] 'supported'
c. [kalimatan țajjibah] [kalimatã tajjibah] 'good word'
d. [man ḍalla] [mã ḍalla] 'who have gone astray'

Similarly, the lateral $/ / /$ is assimilated to emphatic coronals, but not to the gutturals, indicating that emphatic coronals do not constitute a natural class with gutturals. It is important to note that $/ \mathrm{q} / \mathrm{behaves}$ similarly to the gutturals. Examples of this process are illustrated with the definite article:

\begin{tabular}{|c|c|c|}
\hline \multicolumn{3}{|c|}{ Lateral assimilation preceding emphatics } \\
\hline e. [?al șabr] & [?aș șabr] & 'the patience' \\
\hline f. [?al tifl] & [?at țifl] & 'the child' \\
\hline [?al qamar] & [?al qamar] & 'the moon' \\
\hline h. [?al haq] & [?al haq] & 'the truth' \\
\hline [?al hawa:?] & [?al hawa:?] & 'the air' \\
\hline
\end{tabular}

According to Alhimlawi (1987), Arabic verbs (perfect and imperfect) with triconsonantal roots can be divided into six verbal paradigms according to the second vowel of the root, as presented in (5). The third verb paradigm $\mathrm{a} / \mathrm{a}$ is usually associated with a guttural consonant. When a guttural precedes this thematic vowel, it is lowered. McCarthy (1994) presents similar data with five verb paradigms supporting the claim that gutturals constitute a natural class. McCarthy explains that the adjacency of the low vowel with a guttural consonant in the a/a class is due to the similar articulatory gesture they share in the pharynx. Although uvulars share similar behaviors with pharyngeals and laryngeals, they do not always lower

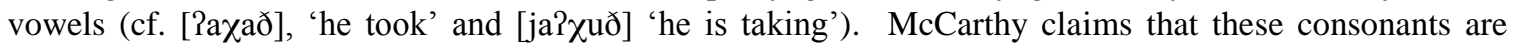
complex, bearing the features [dorsal] and [pharyngeal].

\begin{tabular}{|c|c|c|c|}
\hline Verb-paradigm & perfect & imperfect & \\
\hline g. $\quad a / u$ & naḍar & janḍur & 'look' \\
\hline h. $\quad a / i$ & ḍarab & jaḍrib & 'hit' \\
\hline i. $\quad \mathrm{a} / \mathrm{a}$ & ðahab & jad̆hab & 'go' \\
\hline j. $\quad \mathrm{i} / \mathrm{a}$ & dzahir & jadzhar & 'not see' \\
\hline k. $\quad \mathrm{u} / \mathrm{u}$ & hasun & jahsun & 'be nice' \\
\hline 1. $\quad \mathrm{i} / \mathrm{i}$ & ћasib & jaћsib & 'count' \\
\hline
\end{tabular}

Low vowel epenthesis in guttural (laryngeals, pharyngeals, and uvulars) environments in Bedouin Arabic dialects is supporting evidence that gutturals form a natural class. In these dialects, gutturals are not legal syllable codas. Sequences such as ${ }^{*} \mathrm{CVGCV}$ (where G is a guttural) induce epenthesis (e.g. CVGVCV) in Negev Bedouin Arabic and with the additional elision of the first vowel to form CGVCV in Bedouin Hijazi Arabic (Irshied and Kenstowicz 1984 as mentioned in McCarthy 1994). According to McCarthy, the prohibition of gutturals in syllable codas can be explained by the OCP. Since the low vowel and gutturals are marked with the feature [pharyngeal], the two phonological rules are motivated. The following are examples of guttural roots compared to plain roots.

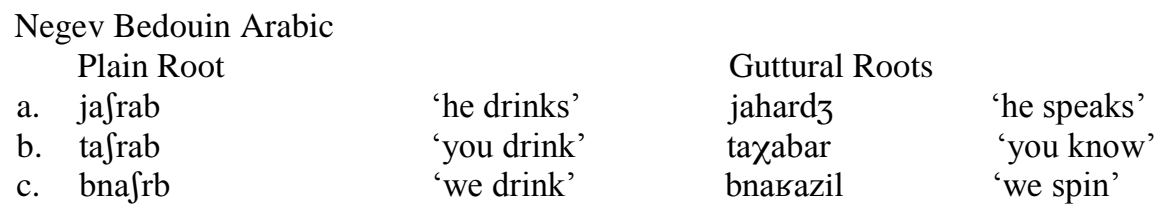




Bedouin Hijazi Arabic
$\quad$ Plain Root
a. jaكrab
b. sawda
c. maktu:b

$\begin{array}{ll} & \text { Guttural Roots } \\ \text { 'he drinks' } & \text { jxadim } \\ \text { 'black' } & \text { bьаӨа } \\ \text { 'written' } & \text { miaðurr }\end{array}$

$$
\begin{aligned}
& \text { 'he serves' } \\
& \text { 'gray' } \\
& \text { 'excused' }
\end{aligned}
$$

Phonetically speaking, the nature of the secondary articulation which makes $/ \mathrm{t} /, / \mathrm{s} /$ contrastive with $/ \mathrm{t} /, / \mathrm{s} /$ is a controversial issue. For example, some studies claim that the tongue dorsum of the emphatics retracts backward with the constriction occurring in the upper pharyngeal region, similar to the articulation of uvulars (Bin-Muqbil 2006; Ghazeli 1977; Shar 2012). On the other hand, other studies argue that the tongue root moves towards the pharynx, and the constriction occurs in the lower pharyngeal region similar to the pharyngeals (Laufer \& Baer 1988). Based on laryngoscopic findings, Hassan and Esling (2011:229) notice that the backing movement of the tongue during the articulation of emphatics "has all the characteristics of tongue raising towards the uvula." From their nasoendoscopic and videofluoroscopic experiments, Al-Tamimi and Heselwood (2011:187) report that the emphatics are articulated with the tongue root retracted and bunched, and they conclude that the constriction involves 'epiglotto-pharyngeal approximation' which occurs at the second and third cervical vertebra region. Based on an acoustic study, Bin-Muqbil (2006) explains that the styloglossus and hyoglossus muscles are responsible for the posterior articulation of the emphatics, as both muscles pull the tongue back towards the pharynx. As for the superior movement, Bin-Muqbil (2006:238) states "the styloglossus raises the back of the tongue while the hyoglossus lowers it." Bin-Muqbil reviewed the images of previous x-rays studies (Al-Ani 1970; Ali \& Daniloff 1972; Ghazeli 1977) and found that there is variability of tongue height in the emphatic articulations due to the antagonistic actions of the two muscles (styloglossus and hyoglossus). The current ultrasound study will enable us to track tongue retraction movement and understand whether the tongue dorsum, the tongue root, or both is/are responsible for the articulation of the emphatics and how they contrast with the pharyngeals and uvulars.

\section{Experiment}

2.1 Hypotheses This paper presents articulatory evidence that the tongue retraction involved in the secondary articulation of the emphatics is phonetically distinct from that of the pharyngeals. In the experiment, (1) we compare tongue retraction of the emphatics to the tongue retraction of the pharyngeals and uvulars; (2) we compare the displacement of the neutral tongue position (tongue root, tongue dorsum, and tongue body) relative to the tongue positions of the emphatics, pharyngeals, and uvulars, and (3) we investigate the coarticulatory effects of the emphatics on the following low vowel /a:/ compared to the pharyngeals and uvulars. The following are three hypotheses tested in this experiment.

a. Tongue retraction for the emphatics and uvulars is different from that of the pharyngeals.

b. Unlike the pharyngeals, tongue root position of the emphatics and uvulars is consistently retracted relative to the neutral position of the tongue root.

c. Low vowel retraction is more evident with the emphatics than the pharyngeals and uvulars.

2.2 Subjects Eight male subjects (3 Yemeni, 2 Egyptian, 2 Saudi, 1 Palestinian) participated in this experiment (labeled Y1, Y2, Y3, E1, E2, S1, S2, P1, respectively). All subjects were students at the University of British Columbia in Vancouver, Canada and their ages ranged between 24-35 years old. None of them reported hearing or speech problems.

2.3 Stimuli The stimulus set (Table 1) was designed to investigate tongue retraction in the emphatic consonants $(/ \mathrm{t} /, / \mathrm{s} /)$ compared to the non-emphatics $(/ \mathrm{t} / / \mathrm{s} /)$, uvulars $(/ \chi /, / \mathrm{s} /)$ and pharyngeals $(/ \mathrm{h} /, / \mathrm{I} /)$. The words used in the experiment were monosyllabic words containing the low long vowel /a:/. The carrier phrase used was [ga:lli ] 'he said to me ', and we used 8 lexical items. The subjects used 
their local varieties to read the words. ${ }^{2}$ In order to avoid the problem of 'scan lag'(Davidson 2012), only the long vowel /a:/ was used.

Table 1: Word list

\begin{tabular}{|c|c|c|c|c|c|c|c|}
\hline Plain & & Emp & & Uvu & & Phary & reals \\
\hline ta:b & 'repented' & ta:b & 'recovered' & $\chi a: b$ & 'failed' & $\hbar a: b$ & 'like' \\
\hline sa:b & 'left' & șa:b & 'targeted' & ба:b & 'was absent' & fa:b & 'didn't like' \\
\hline
\end{tabular}

2.4 Materials A 2-D ultrasound machine (Aloka SSD-5000/ $29.97 \mathrm{fps}$ ) was used in the experiment with an ultrasound probe (UST-9118 endo-vaginal $180^{\circ}$ electronic curved array) and with subjects seated in an ophthalmic examination chair (American Optical Co., model 507-A) with a 2-cup rear headrest. For voice recording, we used a Sennheiser MKH 416 P48 super-cardioid short shotgun condenser interference tube microphone. Ultrasound gel was applied to the skin under the chin of each subject. The ultrasound recordings were transferred to a MacBook laptop.

2.5 Procedures The eight subjects were recorded in the Interdisciplinary Speech Research Lab at the University of British Columbia. Subjects were briefed about the procedures of the experiment. Each subject sat on the chair resting their head against the headrest facing a laptop screen on which they could see the stimuli, where the headrest prevents measurement error (Gick et al. 2005). The ultrasound probe was placed against the neck above the larynx and was set to $90^{\circ}$ to view the complete shape of the tongue. The microphone was positioned with a stand close to the subject's mouth and linked to a desktop where ultrasound videos were recorded. Subjects were presented with the stimulus words on PowerPoint slides. Each slide contained a word in a carrier phrase, and each word was repeated ten times (for a total of 80 tokens).

2.2 Analysis Praat (Boersma \& Weenink 2013) was used to identify and annotate the midpoints of the target consonants and vowels. The midpoint frames were then extracted from the ultrasound videos using a Python script (Allen 2014). After extracting the images of the target segment midpoints, JPEG files were loaded to Edge Trak ( $\mathrm{Li}$ et al. 2003) to trace the tongue curves. ${ }^{3}$ The tongue root, dorsum and body positions were determined for each subject by drawing preliminary angle lines from the transducer center using ImageJ (Rasband 1997). There is no standard method on how to measure the angles for tongue positions; previous studies followed different strategies depending on the target segment being investigated (Allen et al. 2013; Gick et al. 2005; Hudu 2014; Namdaran 2006). Thus, the angle of the tongue root position was specified based on the lowest point at which the tongue root is visible. Since tongue root position is different for consonants and vowels, the tongue root positions were measured for each token and the common angle was selected at which the tongue root is visible for most tokens. The tongue root angles were $41^{\circ}, 35^{\circ}, 53^{\circ}, 35^{\circ}, 30^{\circ}, 37^{\circ}, 37^{\circ}, 35^{\circ}$ for the subjects P1, E1, E2, S1, S2, Y1, Y2, Y3 respectively. Because the study included the uvular sounds, which involve tongue dorsum articulation, we measured the highest point in the tongue dorsum for all the uvular sounds articulated by the subjects. The angles were $64^{\circ}, 58^{\circ}, 68^{\circ}, 59^{\circ}, 61^{\circ}, 53^{\circ}, 62^{\circ}, 53^{\circ}$ for the subjects P1, E1, E2, S1, S2, Y1, Y2, Y3 respectively. Finally, tongue body angle was measured based on the height of the vowels and the neutral position of the tongue

\footnotetext{
${ }^{2}$ There are slight variations across dialects, whereby Palestinian and Egyptian subjects pronounce /g/ as / $/$ /. In this study, 4 subjects (E1, E2, P1, Y3) produce $(/ \chi /, / \mathrm{s} /)$ as velars and 4 subjects (S1, S2, Y1, Y2) produce them as uvulars.

${ }^{3}$ Edge Trak detects the boundary between the tongue surface and the air, and it draws a curve which "changes shape over time until it determines the best edge in an image" (Iskarous, 2005b, as cited in Davidson 2012:489). To use this software effectively, a few points (4-6) have to be chosen manually on the tongue image based on the tongue surface. After that, Edge Trak employs these points to detect and define the tongue curve. The software uses the first tracked image traced as a model to track the tongue curves on the other images. At times manual correction is required. Tongue contours (containing around 30 points) were then extracted as xy coordinates for statistical analysis. In this experiment, each token was traced with 30 points $x 10$ repetitions (=300 points total). The points were exported as xy coordinates in a text file format converted to csv for statistical analysis in R (R Development Core Team 2014). Jeff Mielke's SSANOVA script was used to produce the SSANOVA graphs of the tongue shapes. Unclear images were discarded.
} 
body. The tongue body angles were $91^{\circ}, 95^{\circ}, 93^{\circ}, 98^{\circ}, 99^{\circ}, 99^{\circ}, 102^{\circ}, 102^{\circ}$ for the subjects P1, E1, E2, S1, S2, Y1, Y2, Y3 respectively.

A Smoothing Spline Analysis of Variance (SSANOVA) (Davidson 2006) was employed to statistically compare the means of the tongue shapes during the articulation of the emphatics compared to the nonemphatics, uvulars, and pharyngeals using a Bayesian confidence interval calculated at $p<0.05$. In the SSANOVA plots (Figures 1 and 2), the thicker lines represent the mean of tongue shapes, whereas the thinner lines represent confidence intervals. If the confidence intervals of one data set overlap with those of another data set in the tongue region of interest (for example, tongue root, or tongue body), then there is no significant difference between the two data sets. For reference, the tongue apex is on the left of the images in Figures 1 and 2, the y-axis represents the vertical displacement of the tongue, and the x-axis represents the horizontal displacement of the tongue. Davidson (2012) explains that the SSANOVA takes into account any changes in the shape of the tongue; therefore, no single part of the tongue should be ignored. Therefore, it is ideal to compare the complete shape of the tongue during the articulation of the target sound.

Following Gick et al. (2004) a neutral tongue position was identified in the pauses during inter-speech utterances to act as a baseline from which the postures of speech sounds were compared and measured. This neutral tongue position or 'inter-speech posture' (ISP) is a "period when the articulators had finished moving after articulating the previous sentence/word but before articulators started moving to articulate the following sentence/word" (Gick et al. 2004:4). The neutral tongue position was identified in the middle of the pause between successive carrier phrases. Specifically, the ISP was located within the pause which occurs after the target word and the phrase initial [g] of the following carrier phrase. The ISP was used as a comparative baseline for emphatic, non-emphatic, uvular, and pharyngeal consonants. Moreover, the /a:/ following the emphatic, uvular, and pharyngeal consonants was compared to the /a:/ following the nonemphatic consonants.

Hudu (2014:40) developed the Direct Mapping Hypothesis, which states "that in a language with a lingual harmony (e.g. [ATR], [RTR], [High]) there is a direct mapping between the phonologically active lingual harmonic feature and the position of the relevant part of the tongue". For example, in Dagbani, that vowels require a tongue root position anterior to the tongue root of the ISP indicate that the phonology of that language involves an active [+ATR] feature. According to the hypothesis, languages that contrast vowels based on tongue root gestures are classified into three language categories (A, B, C) depending on the anterior or posterior location of the tongue root from that of the ISP. In each language category, there is one dominant feature. For example, [+ATR] is the dominant feature for category A as in Dagbani and Kinande since the tongue root of the advanced vowels in this language category is consistently anterior to that of the neutral position. With this language category, the tongue root gesture of retracted vowels does not have a consistent and significant displacement from the ISP. In category B, languages (e.g. Yoruba and Tungusic) with the dominant feature [+RTR], the tongue root is significantly and consistently posterior to the ISP of the tongue root. However, in this language category, tongue root position for [-RTR] could be similar, anterior or posterior to the ISP of the tongue root. Finally, category $\mathrm{C}$ includes languages in which both features [+ATR]/ [-ATR] could be phonologically active, as in Turkana, where the tongue root exhibits distinct displacement anteriorly and posteriorly to the neutral tongue root position. The difference between the ISP of the tongue root and the tongue root position for [+ATR] is not greater than the ISP of the tongue root and the tongue root position for [-ATR].

Allen et al. (2013) tested Hudu's predictions in Yoruba vowels using ultrasound, and the results of 3/6 subjects showed that there are general correlations between the tongue-root features and the articulatory positions displaced from ISP. The Direct Mapping Hypothesis can also be extended to include "consonant tongue root positions" (Allen et al. 2013:199). Therefore, Allen et al. tested the hypothesis on St'át'imcets retracted consonants and concluded that retracted consonants retract the tongue root significantly from that of the ISP, concluding that [+RTR] is the dominant tongue root feature. As for the non-retracted consonants, they did not exhibit significant anterior or posterior displacement from the ISP. In this study, we examined the displacement of the tongue root of the emphatics, uvulars, and pharyngeals compared to the tongue root of the ISP and we extended this examination to include tongue dorsum raising as well. 


\section{Results}

Table 2 presents the SSANOVA results of the tongue movements (tongue root [TR], tongue dorsum [TD], and tongue body [TB]) of all of the target consonants (/t $/, / \mathrm{s} /, / \mathrm{t} /, / \mathrm{s} /, / \mathrm{h} /, / \mathrm{s} /, / \chi /, / \mathrm{s} /)$ before $/ \mathrm{a}: /$. For all subjects, results indicate a significant difference in TR position between the emphatics and nonemphatics. All subjects articulated the emphatics with substantial TR retraction compared to the nonemphatic counterparts. Six subjects exhibited a significant difference in TD position between the emphatics and non-emphatics, where TD in the emphatics is backed and higher than that of the nonemphatic counterparts. Table 2 also illustrates that TB position for $/ t /$ and $/ \mathrm{s} /$ for all the subjects is significantly lower when compared to / $\mathrm{t} /$ and $/ \mathrm{s} /$. When comparing emphatics to pharyngeals, the significant difference lies more in the position of TD. For example, the TD of the emphatics is significantly higher than that of the pharyngeals. The results also reveal that the emphatic /t/ retracts TR further than the pharyngeal $/ \hbar /$ for six subjects; the other two participants demonstrated no significant difference. In case of $/ \mathrm{s} /$, the TR position of /ș/ is significantly different from that of $/ \mathrm{S} /$ in three subjects; the other subjects demonstrated no significant difference between $/ \mathrm{s} /$ and $/ \mathrm{S} /$. All subjects except one showed significant TB lowering when articulating $/ t /$ compared to the articulation of $/ \hbar /$. Similarly, the TB difference between $/ \mathrm{s} /$ and $/ \mathcal{S} /$ is significant for four subjects. Compared to uvulars, most subjects articulated the emphatics with further TR retraction accompanied with TD lower than the uvulars. TB lowering is more evident in /t/ compared to $/ \chi /$ than $/ \mathrm{s} /$ compared to $/ \mathrm{b} /$. Figure 1 presents these findings; due to space limitation, we present the SSANOVA graphs only for $(/ \mathrm{t} /, / \mathrm{t} /, / \mathrm{h} /, / \chi /$ before the low vowel $/ \mathrm{a}: /)$.

Table 2: Tongue positions of the emphatics compared to their nonemphatic counterparts, uvulars and pharyngeals before the low vowel /a:/ in terms of tongue dorsum height $(\neg, \downarrow)$, tongue root backness $(\leftarrow-$ $\rightarrow)$ and tongue body lowering $(\wedge, \vee)$. $(\nearrow=$ higher; $\downarrow=$ lower; $\leftarrow=$ advanced; $\rightarrow=$ retracted; $\wedge=$ higher; $\vee=$ lower; $==$ equal/no significant difference). The symbols indicate the behavior of tongue positions for the first condition compared to the second one.

\begin{tabular}{|c|c|c|c|c|c|c|c|c|}
\hline Conditions & $\mathrm{Y} 1$ & $\mathrm{Y} 2$ & Y3 & P1 & E1 & E2 & S1 & S2 \\
\hline ț/_a: : t/_a: & $\rightarrow \nearrow \vee$ & $\rightarrow \nearrow \vee$ & $\rightarrow \nearrow \vee$ & $\rightarrow \nearrow \vee$ & $\rightarrow \nearrow \vee$ & $\rightarrow \nearrow \vee$ & $\rightarrow=\vee$ & $\rightarrow=\vee$ \\
\hline ș/_a: : s/_a: & $\rightarrow \nearrow \vee$ & $\rightarrow \nearrow \vee$ & $\rightarrow \nearrow \vee$ & $\rightarrow \nearrow \vee$ & $\rightarrow \nearrow \vee$ & $\rightarrow \nearrow \vee$ & $\rightarrow=\vee$ & $\rightarrow=\vee$ \\
\hline t/_a: : h/_a: & $\rightarrow \nearrow \vee$ & $=\nearrow \vee$ & $\rightarrow \nearrow \vee$ & $\rightarrow \nearrow \vee$ & $\rightarrow=\vee$ & $=\nearrow \vee$ & $\rightarrow \nearrow \vee$ & $===$ \\
\hline ș/_a: : S/_a: & $=\nearrow \vee$ & $\leftarrow \nearrow \vee$ & $\rightarrow \nearrow=$ & $\rightarrow \lambda=$ & $=\lambda=$ & $=\nearrow \vee$ & $\rightarrow \nearrow \vee$ & $==\wedge$ \\
\hline t/_a: : $\chi / \_a:$ & $=\downarrow \vee$ & $=\downarrow \vee$ & $\rightarrow=\vee$ & $\rightarrow \downarrow \vee$ & $\rightarrow \downarrow \vee$ & $\rightarrow=\vee$ & $\rightarrow \downarrow=$ & $\rightarrow \downarrow \vee$ \\
\hline ș/a: : b/_a: & $=\downarrow \vee$ & $\rightarrow \downarrow=$ & $\rightarrow \downarrow=$ & $\rightarrow \downarrow=$ & $\rightarrow \downarrow \vee$ & $\rightarrow=\vee$ & $=\downarrow=$ & $=\downarrow \wedge$ \\
\hline
\end{tabular}

Table 3 below summarizes the comparisons between the tongue positions (tongue root [TR], tongue dorsum [TD], and tongue body [TB]) of the ISP and the respective tongue positions of the emphatics, nonemphatics, pharyngeals and uvulars for each subject. As demonstrated by almost all subjects, the TR position of the emphatics is consistently and significantly posterior to the TR position of the ISP. TR retraction of the emphatics is consistent with TB position lower than that of the ISP. TD positions generally show no difference between the ISP and the emphatics except for two subjects who articulated the emphatics with TD higher than of the TD of the ISP. With regards to the nonemphatics, they advance the TR position and lower TD position compared to the ISP positions of TR and TD. Turning to pharyngeals, four subjects exhibited significant TR retraction relative to the ISP; however, the other four subjects showed no significant difference in displacement. All subjects except one produced the pharyngeals with TD that is significantly lower relative to the TD position of the ISP. Apart from the significant raising of TD of uvulars compared to the TD-ISP, the TR of uvulars is posterior to the ISP for most of the subjects. TB locations of the uvulars are generally lower than the TB-ISP. 

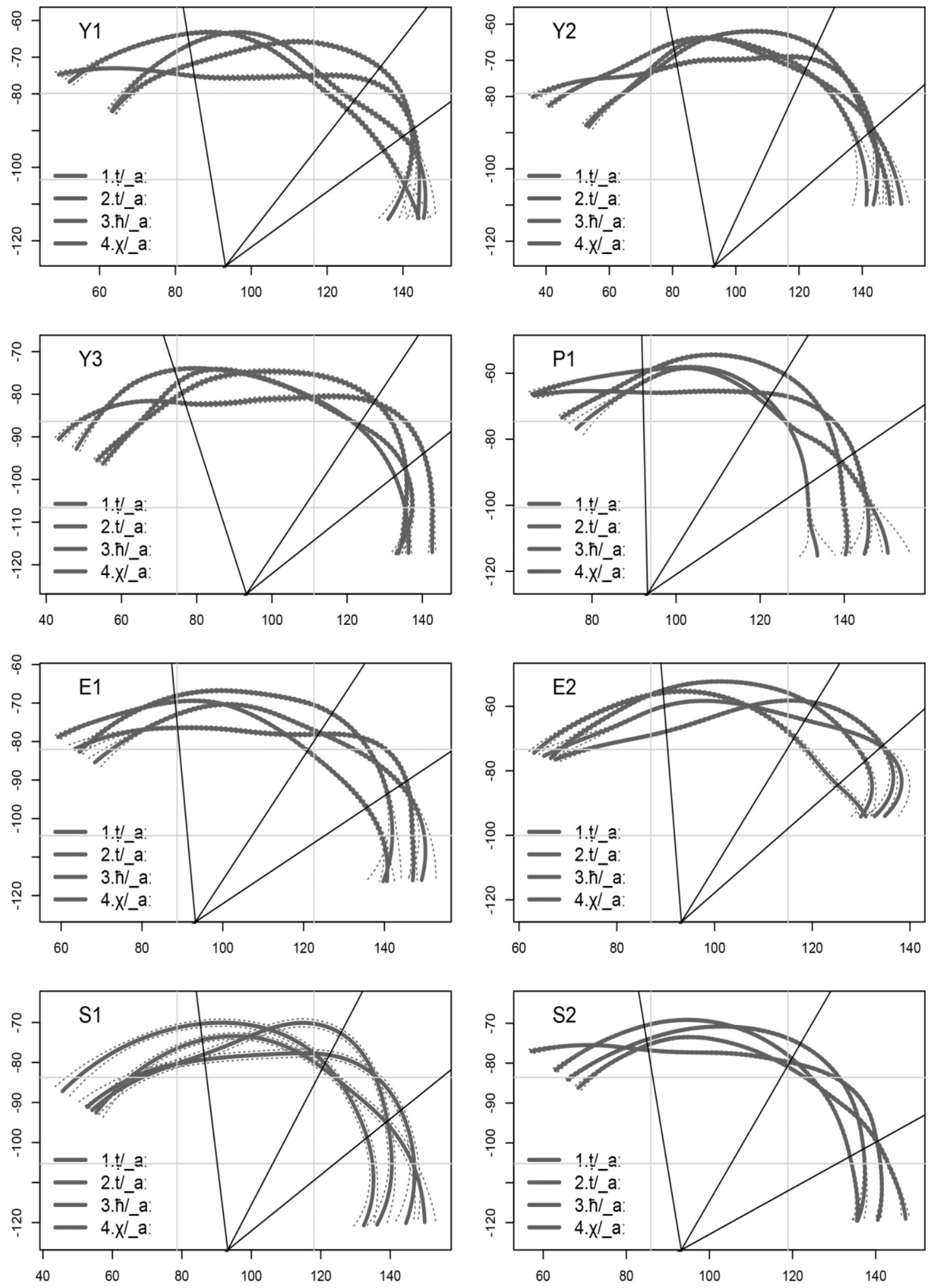

Figure 1. SSANOVA results of tongue surfaces of the emphatic $/ \mathrm{t} /$, nonemphatic $/ \mathrm{t} /$, pharyngeal $/ \mathrm{h} /$, and uvular $/ \chi /$.The three lines starting from the right indicate the angles of tongue root (TR), tongue dorsum (TD), and tongue body (TB). Color versions of these figures are provided in the supplementary files. 

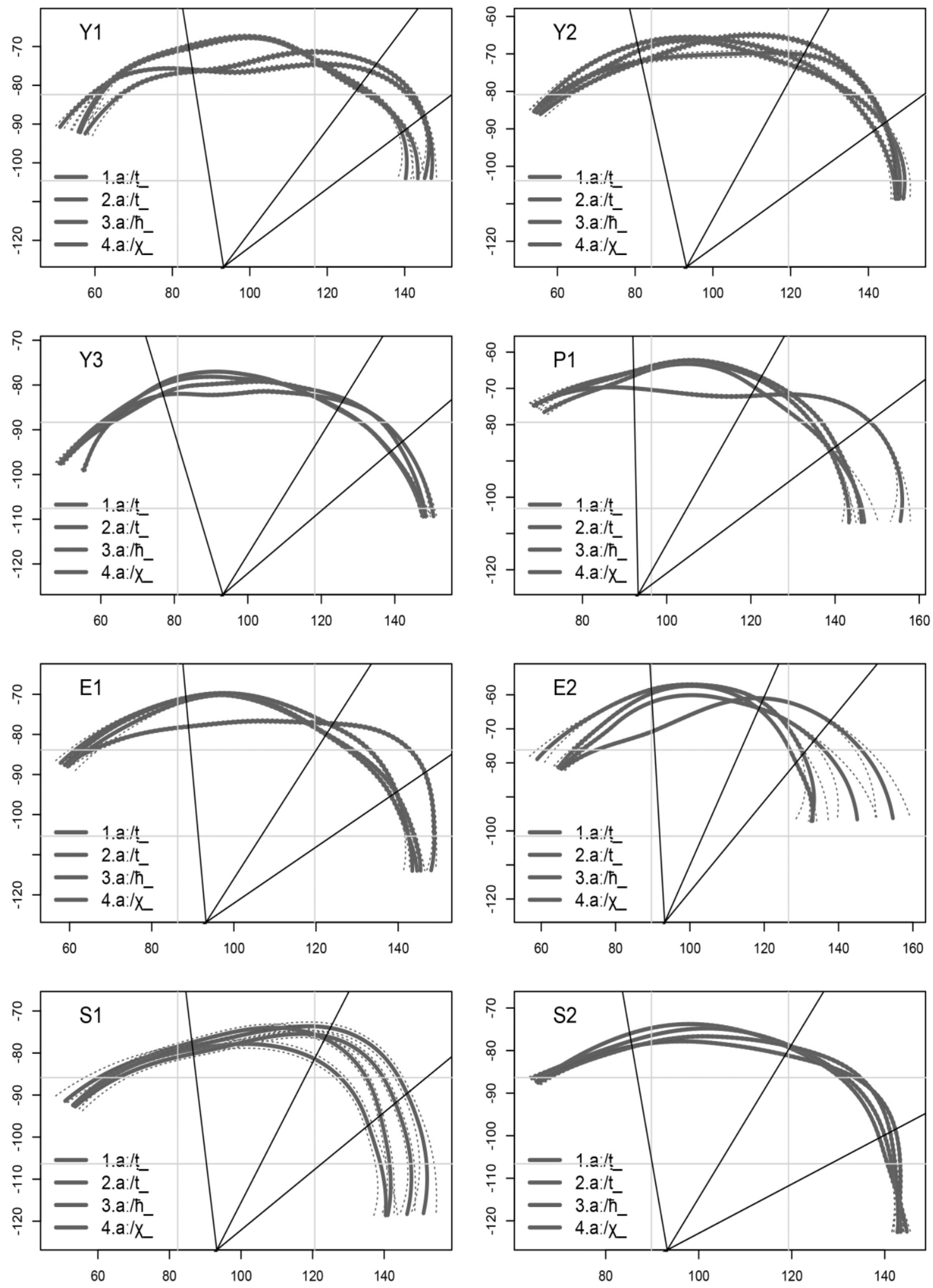

Figure 2. SSANOVA results of tongue surfaces of the low vowel /a:/ preceded by the emphatic /t $/$, nonemphatic $/ \mathrm{t} /$, pharyngeal $/ \hbar /$, and uvular $/ \chi /$. The three lines starting from the right indicate the angles of tongue root (TR), tongue dorsum (TD), and tongue body (TB). Color versions of these figures are provided in the supplementary files 
Table: 3 Tongue positions of ISP relative to the tongue positions of the emphatics, nonemphatics, uvulars and pharyngeals. The symbols show the behavior of tongue positions for the first condition compared to the second one.

\begin{tabular}{|c|c|c|c|c|c|c|c|c|}
\hline Conditions & Y1 & $\mathrm{Y} 2$ & Y3 & $\mathrm{P} 1$ & E1 & E2 & S1 & $\mathrm{S} 2$ \\
\hline t/_a: :ISP & $\leftarrow \downarrow \wedge$ & $\leftarrow \downarrow=$ & $\leftarrow \downarrow=$ & $\leftarrow \downarrow \wedge$ & $\leftarrow \downarrow=$ & $\leftarrow \downarrow=$ & $\leftarrow \downarrow=$ & $===$ \\
\hline s/_a: : ISP & $\leftarrow \downarrow=$ & $\leftarrow \downarrow \vee$ & $=\downarrow=$ & $\leftarrow=\wedge$ & $\leftarrow \downarrow \vee$ & $\leftarrow \downarrow \vee$ & $\leftarrow \downarrow \vee$ & $=\downarrow \wedge$ \\
\hline ț_a: : ISP & $\rightarrow=\vee$ & $\rightarrow=\vee$ & $\rightarrow \nearrow \vee$ & $\rightarrow=\vee$ & $\rightarrow \downarrow \vee$ & $\rightarrow \nearrow \vee$ & $\rightarrow=\vee$ & $\rightarrow \downarrow \vee$ \\
\hline ș/_a: : ISP & $\rightarrow=\vee$ & $==\vee$ & $\rightarrow \nearrow \vee$ & $\rightarrow==$ & $\rightarrow=\vee$ & $\rightarrow \nearrow \vee$ & $\rightarrow=\vee$ & $\rightarrow=\vee$ \\
\hline ћ/_a: : ISP & $=\downarrow=$ & $\rightarrow \downarrow \vee$ & $=\downarrow \vee$ & $=\downarrow=$ & $\rightarrow \downarrow \vee$ & $\rightarrow=\vee$ & $=\downarrow \vee$ & $\rightarrow \downarrow \vee$ \\
\hline I/_a: : ISP & $=\downarrow=$ & $\rightarrow \downarrow \vee$ & $=\downarrow \vee$ & $=\downarrow=$ & $\rightarrow \downarrow \vee$ & $\rightarrow=\vee$ & $=\downarrow \vee$ & $\rightarrow \downarrow \vee$ \\
\hline 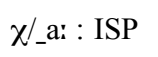 & $\rightarrow \nearrow \vee$ & $=\nearrow \mathrm{V}$ & $\rightarrow \nearrow \vee$ & $\rightarrow \nearrow \wedge$ & $\rightarrow \nearrow=$ & $\rightarrow \nearrow=$ & $=\nearrow \vee$ & $\rightarrow \nearrow \vee$ \\
\hline b/_a: : ISP & $\rightarrow \nearrow \vee$ & $\rightarrow \nearrow \vee$ & $\rightarrow \nearrow \vee$ & $\rightarrow \nearrow=$ & $\rightarrow=\vee$ & $\rightarrow \nearrow=$ & $=\nearrow \mathrm{V}$ & $\rightarrow=\vee$ \\
\hline
\end{tabular}

Table 4 and Figure 2 illustrate the coarticulatory effects of the emphatics, pharyngeals, and uvulars on the midpoint of the following low vowel /a:/. Due to space limitation, we present the SSANOVA graphs only for /a:/ preceded by the emphatic /t!/, nonemphatic $/ t /$, pharyngeal $/ \hbar /$, and uvular $/ \chi /$. We consider the low vowel /a:/ following the nonemphatics to be the baseline vowel against which we compare it to the /a:/ following $(/ \mathrm{t} /, / \mathrm{s} /, / \mathrm{h} /, / \mathrm{S} /, / \chi /, / \mathrm{s} /)$. The SSANOVA curves demonstrate that the two emphatics $/ \mathrm{t} /$ and $/ \mathrm{s} /$ induce consistent and significant TR backing for /a:/ across all subjects. The emphatics also retract the TD of /a:/ towards the uvula and lower the TB for most subjects. Similarly, the /a:/ in the uvular environment is distinct from the baseline vowel /a:/. For example, all the subjects demonstrated TR retraction of /a:/ following $/ \chi /$ and most subjects raised the TD of /a:/. The uvular /丂/ show similar tongue gestures but less evident than the $/ \chi /$. In contrast, the /a:/ in the pharyngeal environment does not exhibit such significant and consistent gestures compared to the /a:/ in the emphatic and uvular environment. Although both emphatics and uvulars cause relatively similar coarticulatory effects on the low vowel, the emphatics have more pronounced effects on this vowel in terms of TR retraction as presented in the Table 5.

Table 4: Comparison of the coarticulatory effects of the nonemphatics, emphatics, uvulars and pharyngeals on /a:/. Symbols indicate the behavior of tongue positions for the first condition compared to the second.

\begin{tabular}{|c|c|c|c|c|c|c|c|c|}
\hline Conditions & Y1 & Y2 & Y3 & $\mathrm{P} 1$ & E1 & E2 & S1 & $\mathrm{S} 2$ \\
\hline $\mathrm{a} / \mathrm{t}{ }_{-}: \mathrm{a}_{2} / \mathrm{t}$ & $\rightarrow \nearrow \vee$ & $\rightarrow=\vee$ & $\rightarrow \nearrow \vee$ & $\rightarrow \downarrow \vee$ & $\rightarrow \nearrow \vee$ & $\rightarrow \nearrow \vee$ & $\rightarrow \nearrow=$ & $\rightarrow \downarrow \vee$ \\
\hline a: $/ s_{-}:$a: $/ s_{2}$ & $\rightarrow \nearrow \vee$ & $\rightarrow \nearrow \vee$ & $\rightarrow \nearrow \vee$ & $\rightarrow \downarrow \vee$ & $\rightarrow \nearrow \vee$ & $\rightarrow \nearrow \vee$ & $\rightarrow==$ & $\rightarrow \downarrow \vee$ \\
\hline $\mathrm{a}: / \hbar_{-}: \mathrm{a} / \mathrm{t}_{-}$ & $===$ & $\rightarrow \downarrow \vee$ & $===$ & $=\downarrow=$ & $===$ & $\rightarrow=\vee$ & $\leftarrow \downarrow \vee$ & $\rightarrow=v$ \\
\hline $\mathrm{a}: / \mathrm{s}_{-}: \mathrm{a}: / \mathrm{s}_{-}$ & $===$ & $\rightarrow=\vee$ & $===$ & $=\downarrow=$ & $===$ & $\rightarrow=\vee$ & $===$ & $===$ \\
\hline $\mathrm{a}: \chi_{\sim}: \mathrm{a} / \mathrm{t}_{-}$ & $\rightarrow \nearrow \vee$ & $\rightarrow \nearrow \vee$ & $\rightarrow \nearrow \vee$ & $\rightarrow$ & $\rightarrow \nearrow$ & $\rightarrow \nearrow=$ & $=\mathrm{V}$ & $\rightarrow=\vee$ \\
\hline $\mathrm{a} / \mathrm{s}_{-}: \mathrm{a} / \mathrm{s}_{-}$ & $\rightarrow \nearrow \vee$ & $\rightarrow \nearrow \vee$ & $\rightarrow==$ & $===$ & $===$ & $\rightarrow==$ & $===$ & $\rightarrow \downarrow \vee$ \\
\hline
\end{tabular}

Table 5: Comparison of degrees of low vowel retraction between emphatics, uvulars, and pharyngeals. Symbols indicate the behavior of tongue positions for the first condition compared to the second.

\begin{tabular}{|c|c|c|c|c|c|c|c|c|}
\hline Conditions & $\mathrm{Y} 1$ & Y2 & Y3 & $\mathrm{P} 1$ & E1 & E2 & $\mathrm{S} 1$ & $\mathrm{~S} 2$ \\
\hline a: $/ t_{-}: a^{2} / h_{-}$ & $\rightarrow \nearrow \vee$ & $=\nearrow \mathrm{V}$ & $\rightarrow \nearrow \vee$ & $\rightarrow \downarrow \vee$ & $\rightarrow \nearrow \vee$ & $\rightarrow \nearrow \vee$ & $\rightarrow \nearrow=$ & $\rightarrow \downarrow \vee$ \\
\hline a: $/ s_{-}:$a: $/ \Upsilon_{-}$ & $\rightarrow \nearrow \vee$ & $=\nearrow=$ & $\rightarrow=\vee$ & $\rightarrow \downarrow \vee$ & $\rightarrow \nearrow \vee$ & $\rightarrow \nearrow \vee$ & $\rightarrow==$ & $\rightarrow \downarrow=$ \\
\hline a: $/ t_{-}: a_{i} / \chi_{-}$ & $=\downarrow=$ & $=\downarrow=$ & $===$ & $\rightarrow \downarrow \vee$ & $\rightarrow=\vee$ & $\rightarrow=\vee$ & $\rightarrow==$ & $\rightarrow \downarrow=$ \\
\hline a:/ș_: a:/s_ & $===$ & $===$ & $===$ & $\rightarrow \downarrow \vee$ & $\rightarrow \nearrow \vee$ & $\rightarrow \nearrow \vee$ & $\rightarrow==$ & $=\wedge \wedge$ \\
\hline
\end{tabular}




\section{Discussion and conclusion}

As explained in the first section of the paper, the assignment of the retracted tongue root feature [RTR] to the emphatics, pharyngeals, and uvulars is problematic phonologically as it first poses problems to the Obligatory Contour Principle (OCP). The emphatics and pharyngeals do occur freely in the Arabic roots. The second challenge is the nasal and lateral assimilation in the emphatic environment, but not in gutturals environment. The third challenge is the fact that vowels are lowered in the guttural environment, but not in the emphatic environment as in the Bedouin Arabic dialects. These challenges indicate that these sounds must have different phonetic representation. Therefore, the present ultrasound study has allowed us to investigate the tongue movements (tongue root [TR], tongue dorsum [TD], and tongue body [TB]) in these sound groups $(/ \mathrm{t} /, / \mathrm{s} /, / \mathrm{t} /, / \mathrm{s} /, / \hbar /, / \mathrm{f} /, / \chi /, / \mathrm{s} /$ ) using the Smooth Spline ANOVA (SSANOVA) analysis. In this study, we used the interspeech posture ISP to compare the phonetic displacement of tongue positions for these sound groups compared to the neutral positions. Moreover, we examined the coarticulatory effects of these sound groups on the following low vowel /a:/.

Compared to the nonemphatics and the pharyngeals, the quantitative analysis of the current study reveals that the secondary articulation of the emphatics $/ \mathrm{t} /$ and $/ \mathrm{s} /$ requires simultaneous TD raising for most subjects and consistent TR retraction with TB lowering across all subjects. This account supports previous acoustic studies (Shahin 1996,1997). However, the study rejects the claim that TR retraction in the emphatic production is a by-product of TD raising (Bin-Muqbil 2006; Shar 2012). Based on an acoustic study, Bin Muqbil (2006) suggests that the two extrinsic tongue muscles, the styloglossus, and the hyoglossus, participate in the dorsal retraction of the emphatics. However, the current study proposes that the major extrinsic lingual muscle for their secondary articulation is the styloglossus (in that it pulls the tongue up and back). According to Esling (2005), the hyoglossus pulls the tongue back and down which seems to be the case in the articulation of the pharyngeals. Tongue dorsum retraction in the emphatics is similar to that of the uvulars; however, it is lower. Both emphatics and uvulars involve TR retraction with more retraction required for the emphatics.

When comparing the tracings of TR positions for the emphatic consonants and the TR of the ISP, the emphatics reveal consistent and significant displacement of TR posterior to that of the ISP. This ISP displacement indicates, based on the Direct Mapping Hypothesis (Hudu 2014), that the TR retraction is an active feature of the emphatics as proposed in previous studies (Davis 1995; Rose 1996). In fact, the retraction gesture extends the effect to the low vowel by retracting it, as well. Similar to the emphatics, the uvular consonants retract TR position posterior to the TR position of the ISP, and such TR retraction extends its effect to the neighboring low vowel. Although emphatics and uvulars show similar phonetic patterns, the emphatics are more robust in TR retraction. With regard to the pharyngeals, while only four participants exhibit significant posterior displacement of the TR position relative to the ISP, this does not indicate that the TR retraction feature is an active feature, as there were only two subjects who exhibited low vowel retraction. Therefore, assigning the RTR feature for the pharyngeals (Davis 1995; Rose 1996) is questionable. This raises the question of what phonological specification we need to assign to the pharyngeals since they do not behave like emphatics. Recent studies (Esling 2005; Moisik 2013; Moisik et al. 2011) claim that TR is not the active articulator of the pharyngeals; in fact, TR is a subcomponent of these sounds, and such a gesture does not necessarily retract low vowels. This study supports previous studies (Bin-Muqbil 2006; Shahin 1996,1997; Zawaydeh 1997) in demonstrating that TD retraction/raising involved in the emphatics spreads to the low vowel /a:/.

The phonetic findings reported in this study raise challenges to phonological representations based on the active articulator, or, as Moisik (2013) terms them, 'linguocentric' approaches. For example, in the traditional SPE approach, the emphatics are grouped with the pharyngeals with the features [+low] and [+back]. While our study validates the use of the feature [+back] for emphatics and pharyngeals, the study invalidates the use of the feature [+low] since the tongue dorsum of the emphatics is not low, as seen in the pharyngeals. Moreover, the specification of [-low] to the uvulars is not accurate, as the study demonstrates it is indeed articulated with a high tongue position. Similarly, traditional feature geometric approaches fail to characterize these sound groups. For instance, McCarthy (1994) proposed the feature [pharyngeal] under the place node in order to account for all the gutturals, including the emphatics. However, this approach does not account for the fact that emphatics and pharyngeals co-occur freely in Arabic roots, and it does not account for the tongue root gestures observed in the emphatics and uvulars. Rose (1996) proposes the 
feature [RTR] to be assigned to emphatics, uvulars and pharyngeals, but such a representation does not make a distinction between these sounds, and does not account for the co-occurrence restrictions, as mentioned above. Recent proposals (Bin-Muqbil 2006; Shar 2012) have adapted the Revised Articulator Theory (RAT) (Halle et al. 2000), where the place node dominates only [labial], [coronal], and [dorsal]. Both studies (Bin-Muqbil 2006; Shar 2012) represent the secondary articulation of the emphatics with the tongue body node dominating the features [+back], [-high], and [-low], and make no reference to the tongue root, considering it a by-product of dorsal retraction. These studies also assigned the [RTR] to the pharyngeals; however, the ultrasound shows that TR retraction in the pharyngeals is not as evident as it is in the emphatics. The other approach is a modification of the RAT theory (Halle et al. 2000) and based on Esling (2005) models. The proposed model by Moisik et al. (2011:1) is characterized as "the Phonological version of the Laryngeal Articulator Model" in which they propose including the "epilaryngeal articulator [EPL] as a phonological construct to represent and account for the lingual-laryngeal effects observed in post-velar phonology". In this model, they propose that the feature [retracted] is a Tongue Body feature, and it can also be associated with the EPL (for more details, see (Moisik et al. 2011)). They explain that pharyngeals will be assigned the [retracted] feature if they cause vowel retraction. The ultrasound study validates the feature [retracted] in that retraction is a property of the emphatics since they are mainly articulated with tongue body; however, the pharyngeals lack this feature. The [retracted] feature could also be attributed to the uvulars.

This study used the ultrasound to investigate tongue retraction in the production of the emphatics compared to the nonemphatics, uvulars, and pharyngeals. The emphatics have distinct tongue retraction from that of the pharyngeals. In future research, it is important to consider the lower part of the vocal tract or the laryngeal vocal tract in the sense of (Esling 2005), as this might inform us more about the distinction of the uvulars and emphatics compared to the pharyngeals.

\section{References}

Al-Ani, Salman. (1970). Arabic Phonology: An Acoustical and Physiological Investigation. The Hague: Mouton.

Al-Tamimi, Feda, \& Heselwood, Barry. (2011). Nasoendoscopic, videofluoroscopic and acoustic study of plain and emphatic coronals in Jordanian Arabic. In Zeki Majeed Hassan, \& Barry Heselwood (Eds.), Instrumental Studies in Arabic Phonetics (Vol. 319, pp. 165-191). Amsterdam: John Benjamins.

Alhimlawi, Ahmed. (1987). [shatha al-'urf fi fan alssarf] Introduction to Arabic morphology. Riyadh: Daar Alkayaan.

Ali, Latif , \& Daniloff, Raymond (1972). A contrastive cinefluorographic investigation of the articulation of emphaticnon emphatic cognate consonants. Studia Linguistica, 26(2), 81-105.

Allen, Blake. (2014). Ultrasound Analysis (A package of scripts for processing and analyzing ultrasound data for research in linguistics). Retrieved from https://github.com/bhallen/ultrasound-analysis.

Allen, Blake, Pulleyblank, Douglas, \& Ajíbóyè, Oládiípọ̀. (2013). Articulatory mapping of Yoruba vowels: An ultrasound study. Phonology, 30(02), 183-210.

Archangeli, Diana, \& Pulleyblank, Douglas (1994). Grounded phonology. Cambridge, Mass: MIT Press.

Bin-Muqbil, Musaed. (2006). Phonetic and phonological aspects of Arabic emphatics and gutturals (Doctoral dissertation). University of Wisconsin, Madison, Wisconsin.

Boersma, Paul, \& Weenink, David. (2013). Praat: Doing phonetics by computer (Version 5.3.51). Retrieved from http://www.praat.org

Davidson, Lisa. (2006). Comparing tongue shapes from ultrasound imaging using smoothing spline analysis of variancea. The Journal of the Acoustical Society of America, 120(1), 407-415.

Davidson, Lisa. (2012). Ultrasound as a tool for speech research. The Oxford Handbook of Laboratory Phonology, 484495.

Davis, Stuart. (1995). Emphasis spread in Arabic and grounded phonology. Linguistic Inquiry, 465-498.

Esling, John. (2005). There are no back vowels: The laryngeal articulator model. The Canadian journal of linguistics/La revue canadienne de linguistique, 50(1), 13-44.

Ghazeli, Salem. (1977). Back consonants and backing coarticulation in Arabic (Doctoral dissertation). University of Texas at Austin, Texas.

Gick, Bryan, Pulleyblank, Douglas, Mutaka, Ngessimo, \& Campbell, Fiona. (2005). Low vowels and transparency in Kinande vowel harmony. The Journal of the Acoustical Society of America, 117(4), 2460-2460. $10.1121 / 1.4787265$ 
Gick, Bryan, Wilson, Ian, Koch, Karsten, \& Cook, Clare. (2004). Language specific articulatory settings: Evidence from inter-utterance rest position. Phonetica, 61, 220-233. 10.1159/000084159

Gouda, Ahmed. (1988). Qur'anic recitation : Phonological analysis (Doctoral Dissertation). Georgetown University, D.C.

Halle, Morris, Vaux, Bert, \& Wolfe, Andrew. (2000). On feature spreading and the representation of place of articulation. Linguistic Inquiry, 31(3), 387-444.

Hassan, Zeki, \& Esling, John H. (2011). Investigating the emphatic feature in Iraqi Arabic. Instrumental studies in Arabic phonetics, 319, 217.

Hudu, Fusheini. (2014). [ATR] Feature involves a distinct tongue root articulation: Evidence from ultrasound imaging. Lingua, 143, 36-51.

Laufer, Asher, \& Baer, Thomas. (1988). The emphatic and pharyngeal sounds in Hebrew and in Arabic. Language and speech, 31(2), 181-205.

Li, Min, Kambhamettu, Chandra, \& Stone, Maureen. (2003). EdgeTrak, a program for band-edge extraction and its applications. Paper presented at the Sixth IASTED International Conference on Computers, Graphics and Imaging.

McCarthy, John. (1994). The phonetics and phonology of Semitic pharyngeals.In P. Keating (ed.). Phonological Structure and Phonetic Form: Papers in Laboratory Phonology III, 191-233.

Moisik, Scott. (2013). The epilarynx in speech (Doctoral dissertation). University of Victoria, Victoria.

Moisik , Scott , Czaykowska-Higgins , Ewa, \& Esling, John (2011). The epilaryngeal articulator: A new conceptual tool for understanding lingual-laryngeal contrasts. Paper presented at the meeting for Phonology in the $21 \mathrm{st}$ Century: In Honour of Glyne Piggott (MOT), Montreal, Quebec.

Namdaran, Nahal. (2006). Retraction in St'a't'imcets: An Ultrasound Investigation (Master thesis). University of British Columbia, Vancouver.

R Development Core Team. (2014). R: A language and environment for statistical computing: R Foundation for Statistical Computing.

Rasband, Wayne. (1997). ImageJ software. National Institutes of Health: Bethesda, MD, USA, 2012.

Rose, Sharon. (1996). Variable laryngeals and vowel lowering. Phonology, 13(01), 73-117.

Shahin, Kimary (1996). Accessing pharyngeal place in Palestinian Arabic. Amsterdam Studies in the Theory and History of Linguistic Science, (4), 131-150.

Shahin, Kimary (1997). Acoustics of pharyngealization vs. uvularization harmony. Amsterdam studies in the theory and history of linguistic science, (4), 215-238.

Shar, Saeed. (2012). Arabic emphatics and gutturals: A phonetic and phonological study (Doctoral dissertation). The University of Queensland, Australia.

Zawaydeh, Bushra. (1997). An Acoustic Analysis of Uvularization Spread in Ammani-Jordanian Arabic. Studies in the Linguistic Sciences, 27(1), 185-200. 